Article

\title{
Synthesis and Characterization of Ampholytic Flocculant CPCTS-g-P (CTA-DMDAAC) and Its Flocculation Properties for Microcystis Aeruginosa Removal
}

\author{
Lei Chen ${ }^{1}$, Cuiyun Liu ${ }^{2}$, Yongjun Sun ${ }^{2, *}$, Wenquan Sun ${ }^{2}$, Yanhua $X u^{1}$ and Huaili Zheng ${ }^{3}$ \\ 1 Jiangsu Key Laboratory of Industrial Water-Conservation \& Emission Reduction, College of Environment, \\ Nanjing Tech University, Nanjing 211800, China; matlabvisual@163.com (L.C.); \\ yanhuaxu18@hotmail.com (Y.X.) \\ 2 College of Urban Construction, Nanjing Tech University, Nanjing 211800, China; yunduobai@126.com (C.L); \\ coneflower@163.com (W.S.) \\ 3 Key laboratory of the Three Gorges Reservoir Region's Eco-Environment, State Ministry of Education, \\ Chongqing University, Chongqing 400045, China; zhl@cqu.edu.cn \\ * Correspondence: sunyongjun@njtech.edu.cn; Tel.: +86-025-58139655
}

Received: 13 April 2018; Accepted: 8 May 2018; Published: 11 May 2018

\begin{abstract}
The ampholytic chitosan based flocculant carboxylated chitosan graft-(3-chloro-2hydroxypropyl) trimethylammonium chloride-dimethyl diallyl ammonium chloride (CPCTS-g-P (CTA-DMDAAC)) was synthesized by photo polymerization using carboxylated chitosan (CPCTS), 3-chloro-2-chloropropyltrimethylammonium chloride (CTA) and dimethyldiallylammonium chloride (DMDAAC) as the cationic co-monomers. The effects of monomer concentration, the ratio of CPCTS and cationic monomers, cationic degree, initiator time, photoinitiator concentration, and $\mathrm{pH}$ value on the properties of CPCTS-g-P (CTA-DMDAAC) were studied. The microcystis aeruginosa that was cultured in laboratory was used for CPCTS-g-P (CTA-DMDAAC) flocculation tests. The effects of CPCTS-g-P (CTA-DMDAAC) dosage, $\mathrm{pH}$ value and $\mathrm{G}$ value on flocculation performance were investigated. The maximum removal rate of chlorophyll-a (Chl-a) and chemical oxygen demand (COD) that were obtained by CPCTS-g-P (CTA-DMDAAC) were $98.8 \%$ and $96.5 \%$ under the conditions of dosage $4 \mathrm{mg} / \mathrm{L}, \mathrm{pH} 7$ and $\mathrm{G}$ value $200 \mathrm{~s}^{-1}$, respectively. The flocculation experiments showed that chitosan-based flocculant CPCTS-g-P (CTA-DMDAAC) had better flocculation performance than commercially available flocculants cationic polyacrylamide (CPAM), Polyferric Sulfate (PFS), and polymeric aluminium (PAC).
\end{abstract}

Keywords: chitosan-based flocculant; alga removal; graft copolymerization; photopolymerization; flocculation properties

\section{Introduction}

Eutrophication usually refers to a large amount of nutrients, such as nitrogen and phosphorus, which are needed by organisms; these nutrients are usually discharged into relatively closed water bodies and lakes [1]. In addition, the nutrient substance in the water causes rapid growth of algae, which in turn, has a serious impact on water quality [2]. In severe cases, it can lead to the death of fish and other aquatic organisms. Algae cells were characterized by complex types, large amounts, small specific gravity, high negative charge and high stability [3]. Algae in water has adversely affected drinking water processing and water safety [4]. The algae issue has become a global environmental problem in water environment protection and water treatment [5]. Scientifically and effectively removing algae has become the key to research. 
At present, mainly chemical methods are available for removing algae in research and engineering, such as adding iron salts to remove phosphorus and adding chemical agents to kill algae, but these methods likely cause secondary pollution [6]. Physical methods, such as diversion, mechanical removal of algae, and dredging sediment needs a huge investment in project implementation $[7,8]$. The biological method was mainly conducted through the use of aquatic plants, which release compounds in the water environment to inhibit algae growth, thereby stopping the occurrence of bloom [9]. However, it was worth noting that these methods also have certain limitations. The coagulation method was used to optimize or improve the operation process without changing the existing process conditions of the water plant, such as the type of coagulant, dosage and the dosage method, thereby improving the removal efficiency [10]. The method of coagulation was low in cost and easy to implement, but it did not improve algae removal [11]. The main reason for such failure was the secretion of soluble extracellular organic substances that were composed of nitrogenous substances and pentosan gums by the algae $[12,13]$. When the concentration of algae was high, the sugar and uronic acid that were secreted by algae can form complexes with iron salts and aluminum salts; the presence of such complexes was not conducive to destabilization, thereby resulting in low algae-removing rate of the coagulation process [14]. In recent years, the use of natural modified flocculants for treating alga containing water became an international concern due to the following characteristics: abundant sources, low cost and non-toxic [15].

Carboxylated chitosan (CPCTS) is a carboxylated product that is created by removal of the acetyl group from the chitin [16]. The grafting reaction can be performed on the amino group and on the hydroxyl functional group that was present in the skeleton structure of the carboxylated chitosan [17]. Carboxylated chitosan is one of the most important derivatives of chitosan with high water solubility [18]. Carboxylated chitosan is conducive to the flocculation process; it is used to remove the contaminants and colloidal particles in water by electric charge, thereby achieving efficient pollutant removal. However, it is not applicable to the removal of contaminants and colloidal particles with a negatively charged surface [19]. In order to further improve the positive charge content of CPCTS, the carboxylated chitosan was further modified by a strong cationic monomer to strengthen the positive charge density. An amphoteric chitosan-based flocculant was designed by the introduction of CPCTS and cationic monomer to achieve good flocculation efficiency of both negatively and positively charged contaminants and colloidal particles [20]. In addition, the introduction on chitosan of a lot of linear or cyclic carbohydrates made it obtain good water solubility [21]. Meanwhile, the graft modification by strong cationic monomer had the capacity of changing the hydrophilic-lipophilic balance of CPCTS, giving rise to the formation of hydrophobic pools that can interact with organic matter, colloidal particles and algae [22]. So, the graft modification was applied to prepare an amphoteric chitosan-based flocculant.

In this work, an amphoteric chitosan-based flocculant CPCTS-g-P (CTA-DMDAAC) was successfully prepared by carboxylated chitosan, (3-chloro-2-hydroxypropyl) trimethylammonium chloride and dimethyl diallyl ammonium chloride. The effects of monomer concentration, the ratio of CPCTS and cationic monomers, cationic degree, initiator time, photoinitiator concentration, and the $\mathrm{pH}$ value on the properties of CPCTS-g-P (CTA-DMDAAC) were investigated. The flocculation properties of CPCTS-g-P (CTA-DMDAAC) were systematically tested at different doses and different $\mathrm{pH}$ conditions using alga-containing water, and the comparison between CPCTS-g-P (CTA-DMDAAC) and commercially available chemical water treatment chemicals (CPAM, PFA and PAM).

\section{Materials and Methods}

\subsection{Materials}

Carboxylated chitosan (3-chloro-2-hydroxypropyl)trimethylammonium chloride (50\% in Water) and dimethyl diallyl ammonium chloride $(60 \%$ in water) were obtained from Aladdin Shanghai Biochemical Technology Co., Ltd. (Shanghai, China) Polyferric sulfate, polyaluminum chloride, 
and all the other chemicals were of analytical grade and were sourced from Nanjing Shengjianquan Chemical Glass Instrument Co., Ltd. (Nanjing, China) without further purification. The sample of Microcystis aeruginosa was purchased from the Institute of Hydrobiology, Chinese Academy of Sciences (Wuhan, China).

\subsection{Preparation of CPCTS-g-P (CTA-DMDAAC)}

Solid CPCTS at a certain amount was dissolved in $100 \mathrm{~mL}$ of deionized water, and then CTA and DMDAAC were added into the CMCS solution. After stirring under $\mathrm{N}_{2}$ for 30 min to obtain a homogeneous solution, a certain amount of V50 was added into the CPCTS-CTA-DMDAAC solution before UV irradiation. The UV-initiated graft copolymerization reaction was performed for $60 \mathrm{~min}$. After graft UV-initiated copolymerization, the obtained CPCTS-g-P (CTA-DMDAAC) was washed with ethanol and acetone to remove all of the impurities and was then vacuum-dried at room temperature. The detailed test method of the intrinsic viscosity and grafting behavior was determined based on the Chinese National Standard GB/T 31246-2014.

\subsection{Flocculation Experiments}

The evaluation of flocculation performance was determined by measuring turbidity, chemical oxygen demand (COD) and chlorophyll-a (Chl-a) content. Water quality analysis showed that the turbidity, Chl-a content, COD, and $\mathrm{pH}$ values were $10-30 \mathrm{NTU}, 0.16-0.18 \mathrm{mg} \cdot \mathrm{L}^{-1}, 43-60.0 \mathrm{mg} \cdot \mathrm{L}^{-1}$ and 7.0-8.0, respectively. All of the flocculation experiments were conducted in 1.0 L Plexiglass beakers using a program-controlled jar-test apparatus (ZR4-6, Zhongrun Water Industry Technology Development Co., Ltd., Shenzhen, Guangdong, China) at room temperature. Detailed procedure of the jar tests involved rapid mixing at $400 \mathrm{rpm}$ for $3 \mathrm{~min}$ to ensure the sufficient mixing of flocculants with alga, a slow mixing at $60 \mathrm{rpm}$ for $5 \mathrm{~min}$ for growth of flocs, and finally, a settling period for $15 \mathrm{~min}$ for floc sedimentation. Low $\mathrm{G}$ value was representative for slow mixing, while high $\mathrm{G}$ value was representative for rapid mixing. This procedure was the same as that in our previous work for consideration [23]. Afterward, water samples were collected from the supernatants for further water quality analysis. Each result under the corresponding condition was the average value of triplicate jar tests. COD and turbidity were determined by HACH instrument, and chlorophyll a was measured by Chinese standards (Water quality-Determination of chlorophyll a-Spectrophotometric method) (HJ 897-2017). All of the experimental values that are reported in the text were the average value of three times with relative error was less than $5 \%$.

\section{Results and Discussion}

\subsection{Synthesis of CPCTS-g-P (CTA-DMDAAC)}

\subsubsection{Effect of Total of Monomer Concentration on Intrinsic Viscosity and Grafting Efficiency of CPCTS-g-P (CTA-DMDAAC)}

The effects of the monomer concentration on the intrinsic viscosity and the grafting efficiency are shown in Figure 1. The intrinsic viscosity of CPCTS-g-P (CTA-DMDAAC) increased rapidly with increasing monomer concentration. Then, it increased slowly when the monomer concentration was in the range of $10-20 \%$. When the monomer concentration was more than $25 \%$, the intrinsic viscosity of CPCTS-g-P (CTA-DMDAAC) decreased rapidly. The grafting efficiency of CPCTS-g-P (CTA-DMDAAC) increased with an increasing monomer concentration in the range of $10-25 \%$. When the monomer concentration was more than $25 \%$, grafting efficiency of CPCTS-g-P (CTA-DMDAAC) decreased quickly. When the total monomer concentration was $25 \%$, the optimal intrinsic viscosity and grafting efficiency of CPCTS-g-P (CTA-DMDAAC) were $611.0 \mathrm{~mL} / \mathrm{g}$ and $90.3 \%$, respectively. 


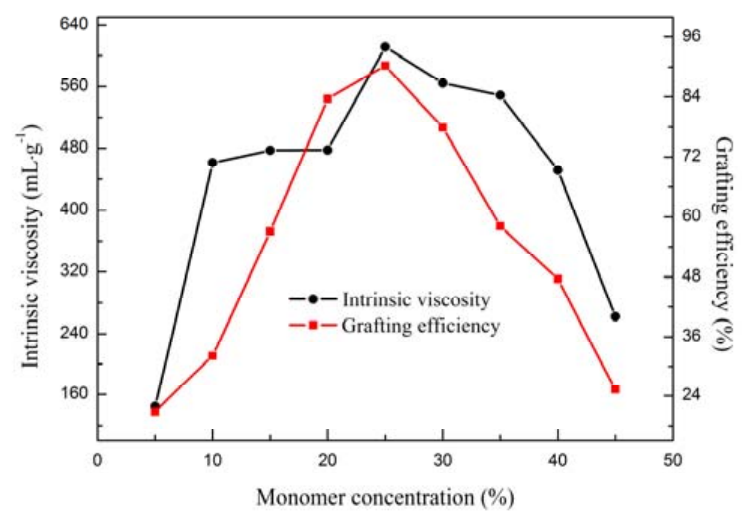

Figure 1. Effect of monomer concentration on intrinsic viscosity and grafting efficiency of carboxylated chitosan (CPCTS)-g-P (CTA-DMDAAC).

The abovementioned phenomenon can be explained in the following discussion. When the monomer concentration was low, the frequency and the probability of collision and chemical reaction between CPCTS, CTA and DMDAAC greatly decreased. Therefore, CPCTS-g-P (CTA-DMDAAC) that is produced by the graft polymerization has a low intrinsic viscosity and grafting efficiency [24]. If the monomer concentration was too high, too many monomers would accumulate in a small place, thereby resulting in the difficulty of electron transfer reactions and reducing reaction efficiency. With an increasing reaction time, monomer molecules can agglomerate to form macromolecular chain, thereby leading to the stickiness of the reaction solution and reaction efficiency decrease [25]. In addition, the sticky reaction solution would hinder the efficient progress of the polymerization reaction and would reduce the solubility of chitosan, thereby resulting in low intrinsic viscosity and grafting efficiency of CPCTS-g-P (CTA-DMDAAC) [26]. In summary, the optimal monomer concentration in the preparation of CPCTS-g-P (CTA-DMDAAC) was 15-35\%.

\subsubsection{Effect of Cationic Degree on Intrinsic Viscosity and Grafting Efficiency of CPCTS-g-P} (CTA-DMDAAC)

The effects of cationic degree on the intrinsic viscosity and grafting efficiency of CPCTS-g-P (CTA-DMDAAC) are shown in Figure 2. The intrinsic viscosity and grafting efficiency of CPCTS-g-P (CTA-DMDAAC) gradually increase first and then decrease progressively after the cationic degree reached $40 \%$. According to the experimental results, the maximum values of the intrinsic viscosity and grafting efficiency of CPCTS-g-P (CTA-DMDAAC) were $852.18 \mathrm{~mL} / \mathrm{g}$ and $93.31 \%$, respectively, which were obtained at a cationic degree of $40 \%$.

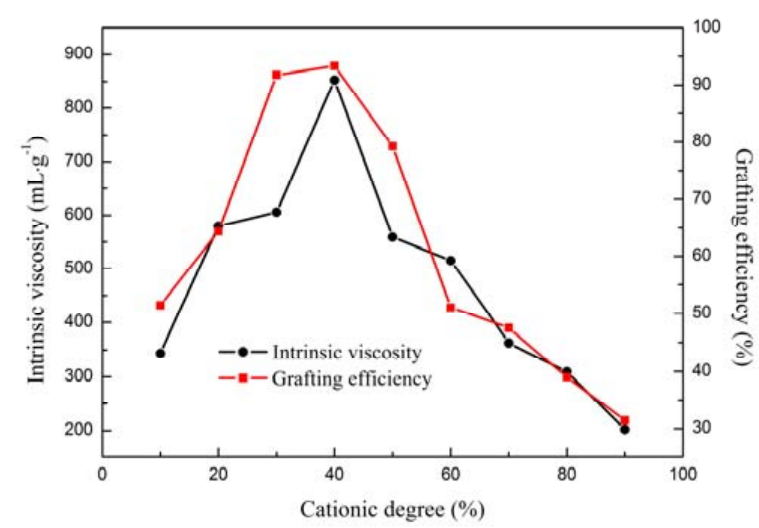

Figure 2. Effect of cationic degree on Intrinsic viscosity and Grafting efficiency of CPCTS-g-P (CTA-DMDAAC). 
A feasible content of cationic degree was positive to achieve CPCTS-g-P (CTA-DMDAAC) with high intrinsic viscosity and grafting efficiency. When the cationic degree was low, and the concentration of CTA and DMDAAC was also low, the high polymerization activity of the cationic monomer enhanced the polymerization reaction [27]. Thus, the intrinsic viscosity and grafting efficiency of CPCTS-g-P (CTA-DMDAAC) increased with an increasing cationic degree [28]. However, when the contents of CTA and DMDAAC were high, bringing the cationic monomers close to one another was difficult due to the electrostatic repulsion between same charges from CTA and DMDAAC [29].

\subsubsection{Effect of Illumination Time on Intrinsic Viscosity and Grafting Efficiency of CPCTS-g-P} (CTA-DMDAAC)

The effect of illumination time on intrinsic viscosity and grafting efficiency of CPCTS-g-P (CTA-DMDAAC) is shown in Figure 3. With increasing illumination time, the intrinsic viscosity and the grafting efficiency of CPCTS-gP (CTA-DMDAAC) gradually increased. When the time reached $100 \mathrm{~min}$, intrinsic viscosity and the grafting efficiency of CPCTS-g-P (CTA-DMDAAC) increased rapidly. When the time exceeded $120 \mathrm{~min}$, the grafting efficiency of CPCTS-g-P (CTA-DMDAAC) increased slowly and then decreased slightly. However, when the illumination time exceeded $120 \mathrm{~min}$, the intrinsic viscosity began to decrease [30].

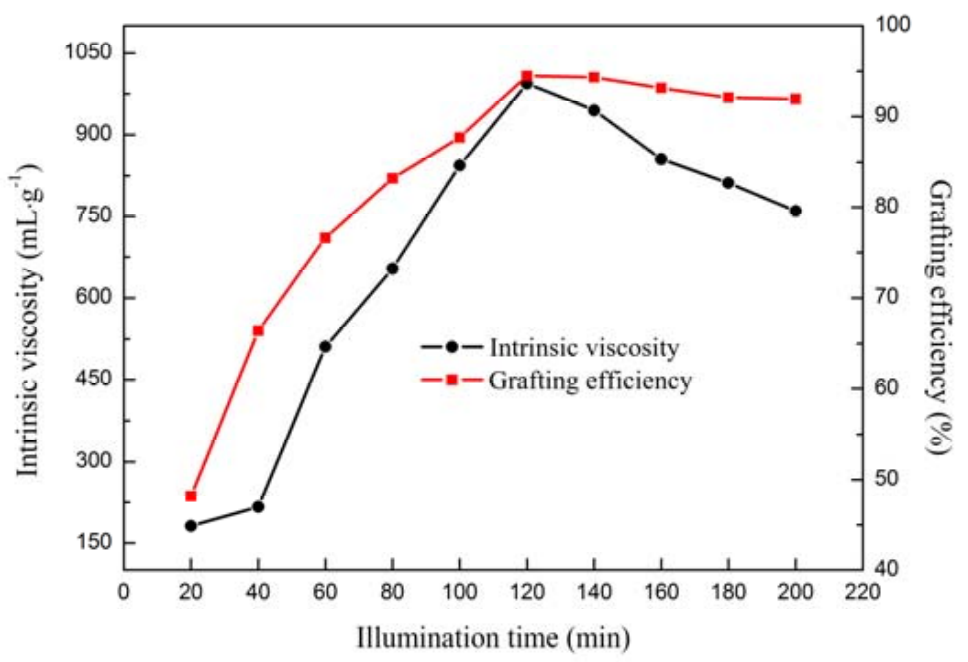

Figure 3. Effect of illumination time on intrinsic viscosity and grafting efficiency of CPCTS-g-P (CTA-DMDAAC).

According to the experimental results, the intrinsic viscosity and the grafting efficiency of CPCTS-g-P (CTA-DMDAAC) reached the maximum values of $993.96 \mathrm{~mL} / \mathrm{g}$ and $94.50 \%$, respectively, at $120 \mathrm{~min}$. A large number of obvious reactive sites generated on the surface of the carboxylated chitosan a short time after the initiation of the reaction [31]. Meanwhile, the photoinitiator V-50 was easily decomposed and it generated a large number of free radicals under UV irradiation, thereby resulting in the fast polymerization between carboxylated chitosan, CTA and DMDAAC. Then, an increase of intrinsic viscosity and grafting efficiency of CPCTS-g-P (CTA-DMDAAC) was obtained in the initial rapid polymerization reaction stage [32]. However, the increase of intrinsic viscosity and grafting efficiency of CPCTS-g-P (CTA-DMDAAC) began to reduce after $120 \mathrm{~min}$. The viscosity of the reaction solution increased with the production of CPCTS-g-P (CTA-DMDAAC). It was difficult for CTA-DMDAAC to diffuse to the vicinity of the CPCTS active center, and the chain growth rate decreased [33]. The graft polymerization stopped with the consumption of the initiator. 
3.1.4. Effect of Photo-Initiator Concentration on Intrinsic Viscosity and Grafting Efficiency of CPCTS-g-P (CTA-DMDAAC)

The effect of the photoinitiator concentration on intrinsic viscosity and the grafting efficiency was shown in Figure 4. As shown in Figure 4, the intrinsic viscosity and grafting efficiency of CPCTS-g-P (CTA-DMDAAC) increased with increasing concentration of photoinitiator at the beginning stage. However, when the photoinitiator concentration was more than $0.50 \%$, the intrinsic viscosity value and grafting efficiency value decreased rapidly. When the photoinitiator (V-50) concentration was $0.5 \%$, the intrinsic viscosity and grafting efficiency of the synthesized CPCTS-g-P (CTA-DMDAAC) reached the maximum values of $784.94 \mathrm{~mL} / \mathrm{g}$ and $96.22 \%$, respectively.

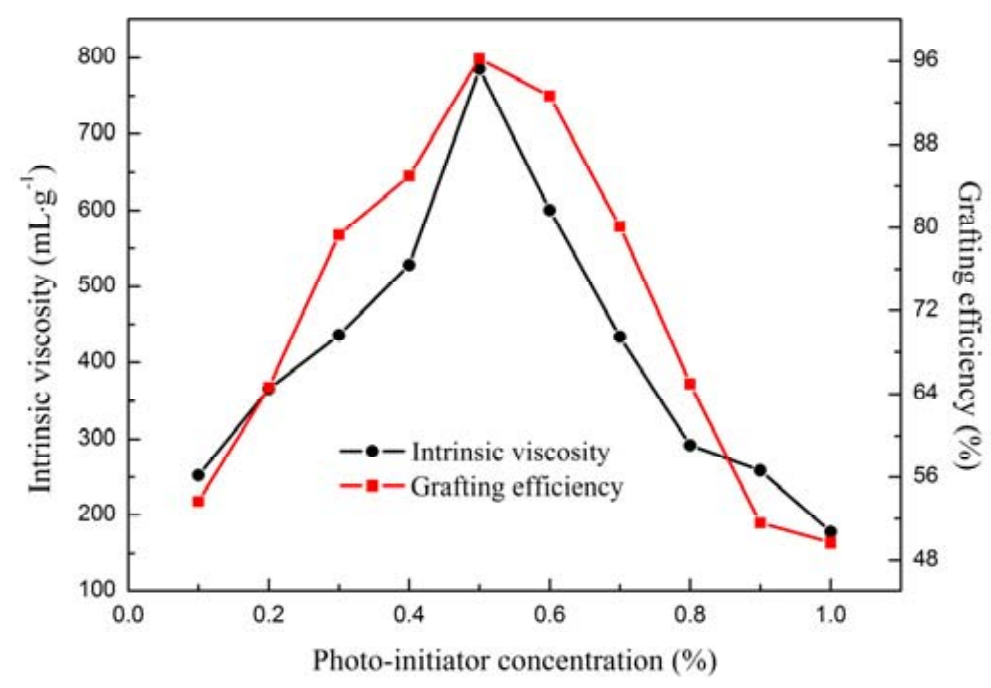

Figure 4. Effect of photo-initiator concentration on Intrinsic viscosity and Grafting efficiency of CPCTS-g-P (CTA-DMDAAC).

With increasing photoinitiator concentration, an increasing number of free radicals are produced via UV irradiation, and the chance of collision between the monomers and free radicals increased [34]. When the photoinitiator concentration increased further, a tremendous amount of free radicals that were generated by UV irradiation intensified the graft polymerization process, thereby leading to implosion and crosslinking between CPCTS, CTA and DMDAAC [35]. Meanwhile, the released heat in the graft copolymerization process could also lead to the cross-linking of CPCTS-g-P (CTA-DMDAAC) cross, thereby resulting in low intrinsic viscosity and grafting efficiency [36]. Therefore, the optimal photoinitiator concentration is $0.4-0.6 \%$ of the initiator concentration.

\subsubsection{Effect of $\mathrm{pH}$ on Intrinsic Viscosity and Grafting Efficiency of CPCTS-g-P (CTA-DMDAAC)}

Figure 5 shows that when the $\mathrm{pH}$ was less than 4 , the intrinsic viscosity and the grafting efficiency of CPCTS-g-P (CTA-DMDAAC) gradually increase with an increasing $\mathrm{pH}$ value. When the $\mathrm{pH}$ was higher than 4 , the intrinsic viscosity and the grafting efficiency of CPCTS-g-P (CTA-DMDAAC) decreased rapidly as the solution transformed from acidic to basic. The optimal values of the intrinsic viscosity and grafting efficiency were $825.9 \mathrm{~mL} / \mathrm{g}$ and $95.7 \%$, respectively. 
The abovementioned results were due to the great influence of the $\mathrm{pH}$ of the reaction solution on the graft copolymerization reaction. When the $\mathrm{pH}$ was lower than 4, CTA and DMDAAC molecules in the graft copolymerization reaction solution were easy to hydrolyze, thereby resulting in the formation of dendritic or cross-linked polymers and in the reduction of the intrinsic viscosity of CPCTS-g-P (CTA-DMDAAC) [37]. The hydroxymethylation reaction occurred easily under neutral or alkaline condition, thereby resulting in a decrease in the intrinsic viscosity and the grafting efficiency of the polymer [38]. Meanwhile, the effect of hydrogen bonding was strengthened by the protonation of most carboxylic acids and quaternary ammonium groups in an acidic environment, thereby playing a negative role in improving the intrinsic viscosity of CPCTS-g-P (CTA-DMDAAC) [39]. Therefore, the optimal $\mathrm{pH}$ range is $4-6$.

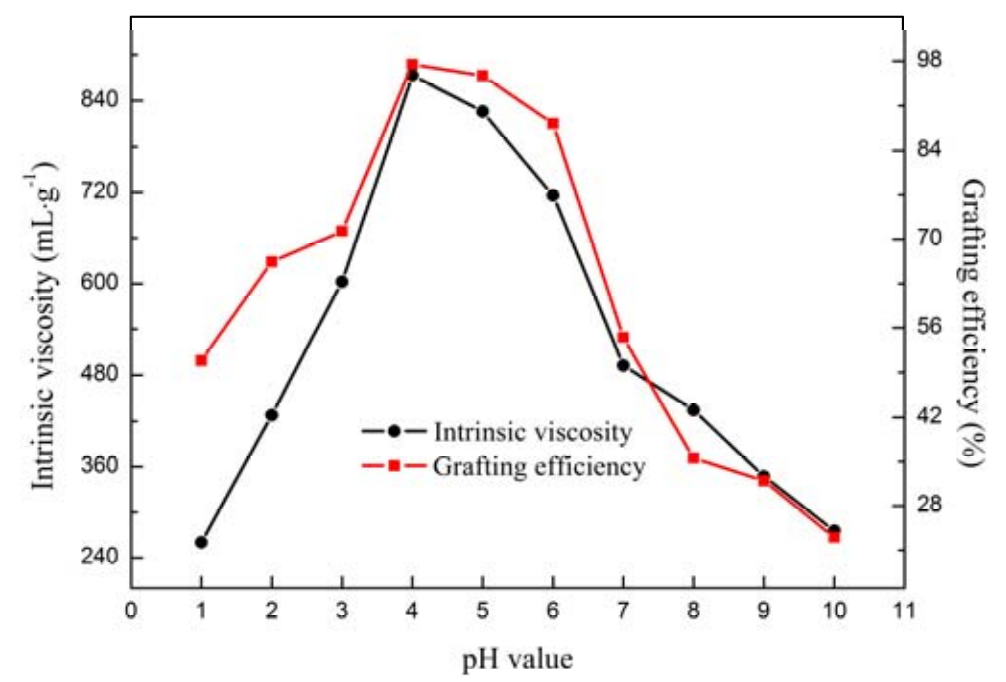

Figure 5. Effect of $\mathrm{pH}$ on intrinsic viscosity and grafting efficiency of CPCTS-g-P (CTA-DMDAAC).

\subsection{Flocculation Experiments}

\subsubsection{Effect of CPCTS-g-P (CTA-DMDAAC) Dosage on Flocculation Properties}

As shown in Figure 6, the removal rate of Chl-a, turbidity, and COD increased with increasing CPCTS-g-P (CTA-DMDAAC) dosage.

CPCTS-g-P (CTA-DMDAAC) and CPAM reached the maximum value of Chl-a, turbidity, and COD at dosage of $4 \mathrm{mg} / \mathrm{L}$. The maximum removal rates of Chl-a obtained by CPCTS-g-P (CTA-DMDAAC) and CPAM were $98.18 \%$ and $86.01 \%$, respectively. The maximum removal rates of COD obtained by CPCTS-g-P (CTA-DMDAAC) and CPAM were $94.93 \%$ and $89.16 \%$, respectively. The maximum removal rates of turbidity that were obtained by CPCTS-g-P (CTA-DMDAAC) and CPAM were $88.71 \%$ and $87.13 \%$, respectively. The optimal dosage range for CPCTS-g-P (CTA-DMDAAC) and CPAM was 3-6 mg/L. PFS and PAC achieved the maximum removal rates of Chl-a, turbidity, and COD at dosages of $30-40 \mathrm{mg} / \mathrm{L}$. the maximum removal rates of Chl-a that were obtained by PFS and PAC were $79.04 \%$ and $67.21 \%$, respectively. The maximum removal rates of turbidity obtained that were by PFS and PAC were $80.95 \%$ and $70.37 \%$, respectively. The maximum removal rates of COD obtained by PFS and PAC were $84.03 \%$ and $86.74 \%$, respectively. Figure 6 shows that the dosages of CPCTS-g-P (CTA-DMDAAC) and CPAM were only about one-tenth of inorganic coagulants dosage, and the optimal removal rate of Chl-a, turbidity, and COD obtained by CPCTS-g-P (CTA-DMDAAC) was higher than that obtained by CPAM and inorganic coagulants dosage [40]. In summary, the optimal dosage of CPCTS-g-P (CTA-DMDAAC) was 3-6 mg/L. 

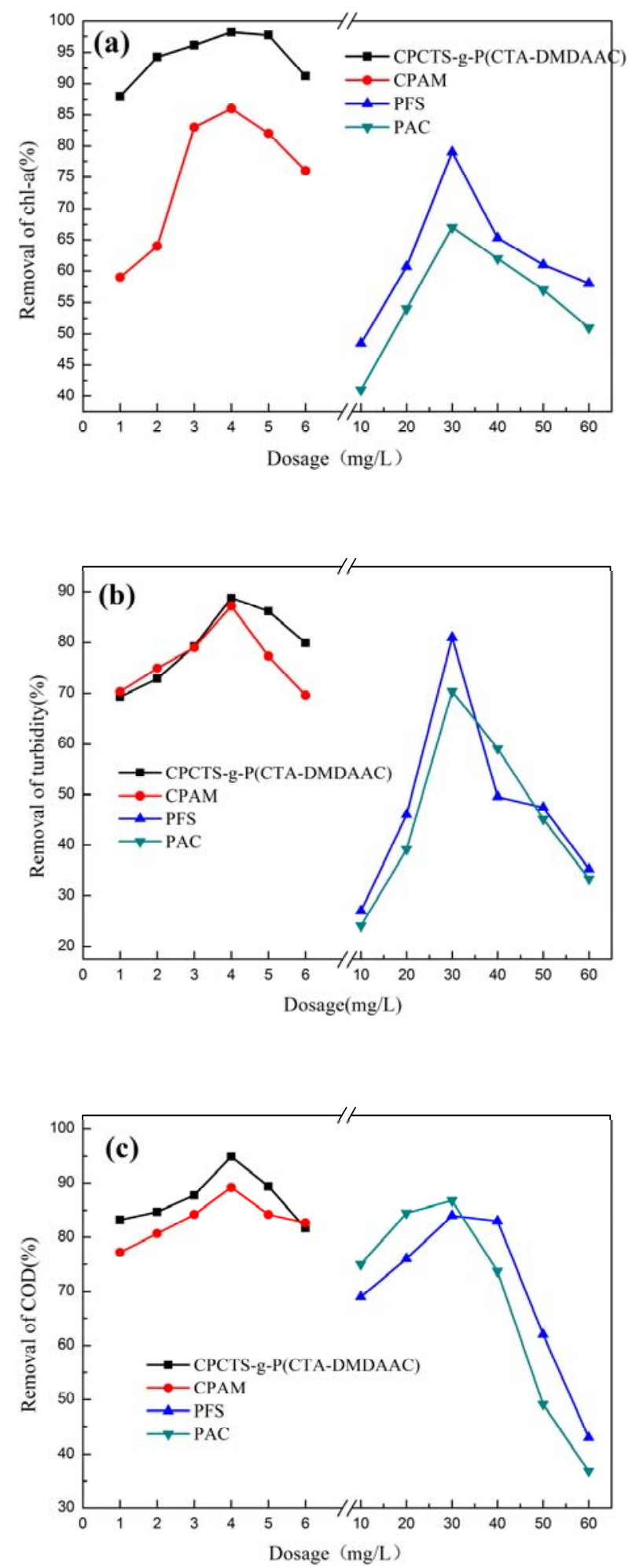

Figure 6. Effect of CPCTS-g-P (CTA-DMDAAC) dosage on flocculation properties: (a) chlorophyll-a (Chl-a); (b) turbidity; (c) chemical oxygen demand (COD).

\subsubsection{Effect of $\mathrm{pH}$ on Flocculation Properties}

As shown in Figure 7, the overall trend of the curve included an initial increase and then a decrease. Chl-a removal rate of CPCTS-g-P (CTA-DMDAAC) increased with increasing raw water $\mathrm{pH}$ value at 
$\mathrm{pH}<7$ in Figure 7a. However, when the $\mathrm{pH}$ value of raw water was $>7$, the removal rate decreased with an increasing $\mathrm{pH}$ value. Thus, the optimal removal rates of CPCTS-g-P (CTA-DMDAAC), CPAM and $\mathrm{PAC}$ at $\mathrm{pH}=7$ were $96.8 \%, 82.2 \%$ and $67.0 \%$, respectively. Maximum flocculation efficiency of PFS that was obtained at $\mathrm{pH} 6$ was $71.6 \%$.
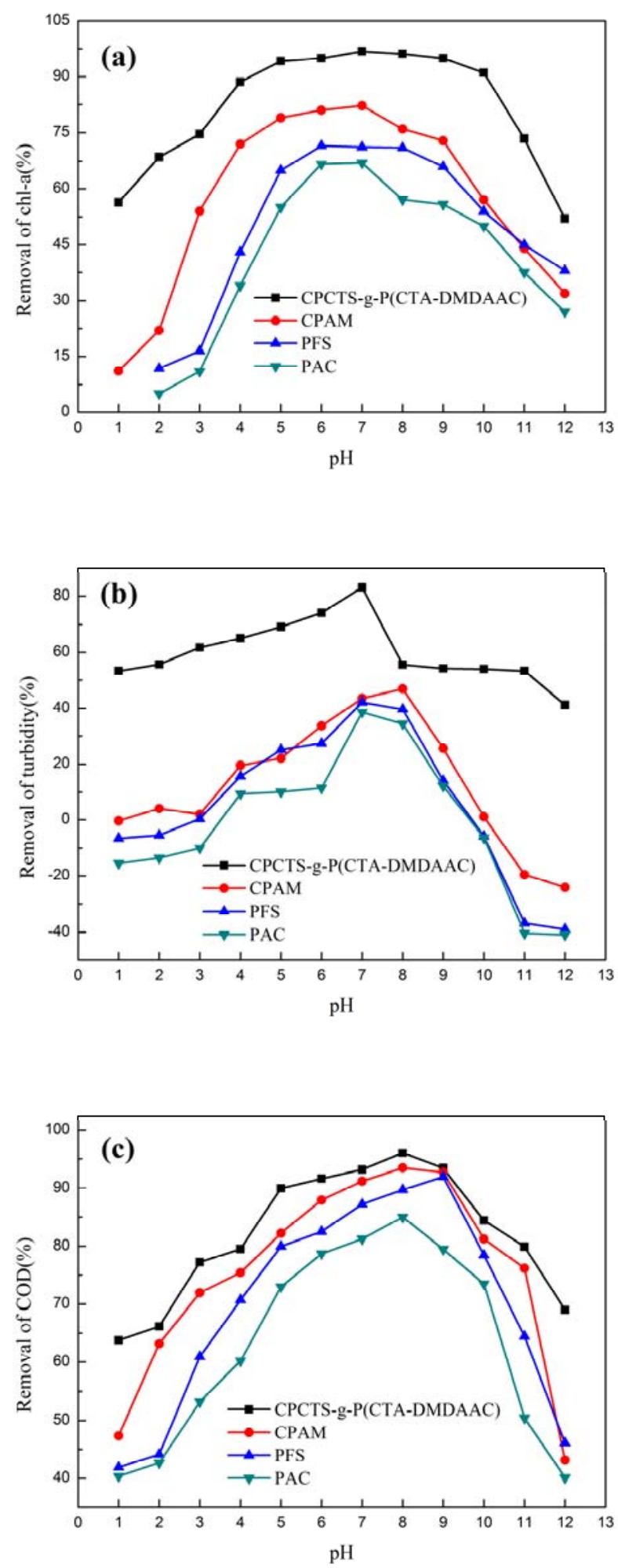

Figure 7. Effect of $\mathrm{pH}$ value on flocculation properties: (a) Chl-a; (b) turbidity; (c) COD removal. 
As shown in Figure 7b, the removal rate of turbidity obtained by CPCTS-g-P (CTA-DMDAAC) and $\mathrm{PAC}$ increased with increasing raw water $\mathrm{pH}$ value when the $\mathrm{pH}$ was $<7$. When the $\mathrm{pH}$ was $>7$, the removal rate of turbidity decreased accordingly. The optimal turbidity removal rate that was obtained by CPCTS-g-P (CTA-DMDAAC) and PAC at $\mathrm{pH}=7$ were $83.1 \%$ and $38.6 \%$, respectively. However, the turbidity removal rate obtained by CPAM and PFS increased with an increasing $\mathrm{pH}$ at $\mathrm{pH}$ values of $<8$. When $\mathrm{pH}$ was $>8$, the turbidity removal rate that was obtained by CPAM and PFS decreased [41]. So, at $\mathrm{pH}=8$, the turbidity removal rate of CPAM and PFS reached the maximum values of $46.91 \%$ and $42.15 \%$, respectively. As shown in Figure $7 \mathrm{c}$, the removal rate of COD that was achieved by CPCTS-g-P (CTA-DMDAAC), CPAM and PAC increased with increasing $\mathrm{pH}$ value at $\mathrm{pH} 1-8$. When the $\mathrm{pH}$ was higher than 8 , the removal rate of COD achieved by CPCTS-g-P (CTA-DMDAAC) decreased. Therefore, the removal rates achieved by CPCTS-g-P (CTA-DMDAAC), CPAM and PAC reached maximum values of $96.0 \%, 93.5 \%$ and $85.0 \%$ at $\mathrm{pH}=8$, respectively. By contrast, the optimal removal rate of COD that was obtained by PFS was $92.0 \%$. In summary, the optimal $\mathrm{pH}$ value of CPCTS-gP (CTA-DMDAAC) for removing Chl-a and COD was 6-9.

\subsubsection{Effect of G Value on Flocculation Properties}

The effect of hydraulic conditions on (a) Chl-a, (b) turbidity and (c) COD are shown in Figure 8. As shown in Figure 8a, Chl-a removal rate of CPCTS-gP (CTA-DMDAAC), CPAM, PFS and PAC reached the maximum values of $98.8 \%, 89.4 \%, 93.7 \%$ and $93.5 \%$ at a value of $200 \mathrm{~s}^{-1}$, respectively. The removal efficiency of Chl-a increased with an increasing $\mathrm{G}$ value at $\mathrm{G}$ value $<200 \mathrm{~s}^{-1}$, but the removal rate of Chl-a from CPAM, PFS and PAC quickly decreased when the G value was more than $200 \mathrm{~s}^{-1}$. The removal rate of Chl-a that was obtained by CPCTS-g-P (CTA-DMDAAC) decreased slowly. As shown in Figure 8b, the removal rate of turbidity achieved by PAC and PFS showed a negative value at $G$ value $100-150 \mathrm{~s}^{-1}$, thereby indicating that the low $G$ value was disadvantageous for the flocculation of PAC and PFS, i.e., the turbidity increased and the $G$ value of the optimal condition for turbidity removal was $250 \mathrm{~s}^{-1}$. The maximum turbidity removal rates that were obtained by CPCTS-g-P (CTA-DMDAAC) and CPAM were $81.1 \%$ and $69.7 \%$, respectively. As shown in Figure $8 \mathrm{c}$, the $G$ value for optimal COD removal was $200 \mathrm{~s}^{-1}$. CPCTS-g-P (CTA-DMDAAC) and CPAM had higher COD removal rate than PAC and PFS in the $G$ value tat was investigated. In addition, higher $G$ value did not cause serious reduction of COD removal obtained by CPCTS-g-P (CTA-DMDAAC) and CPAM, which indicated that CPCTS-g-P (CTA-DMDAAC) had better resistance to hydraulic shear [42]. Therefore, the optimal flocculation performance for treating algae-infested water with CPCTS-g-P (CTA-DMDAAC) was 150-250 s ${ }^{-1}$.

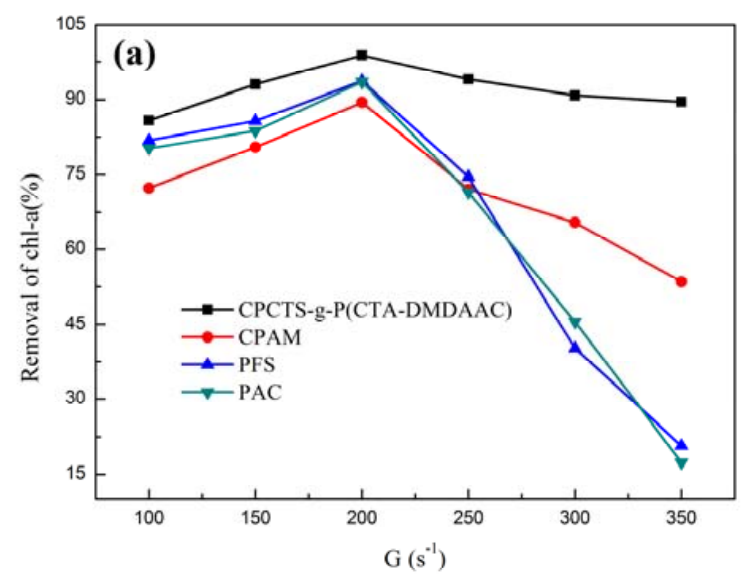

Figure 8. Cont. 

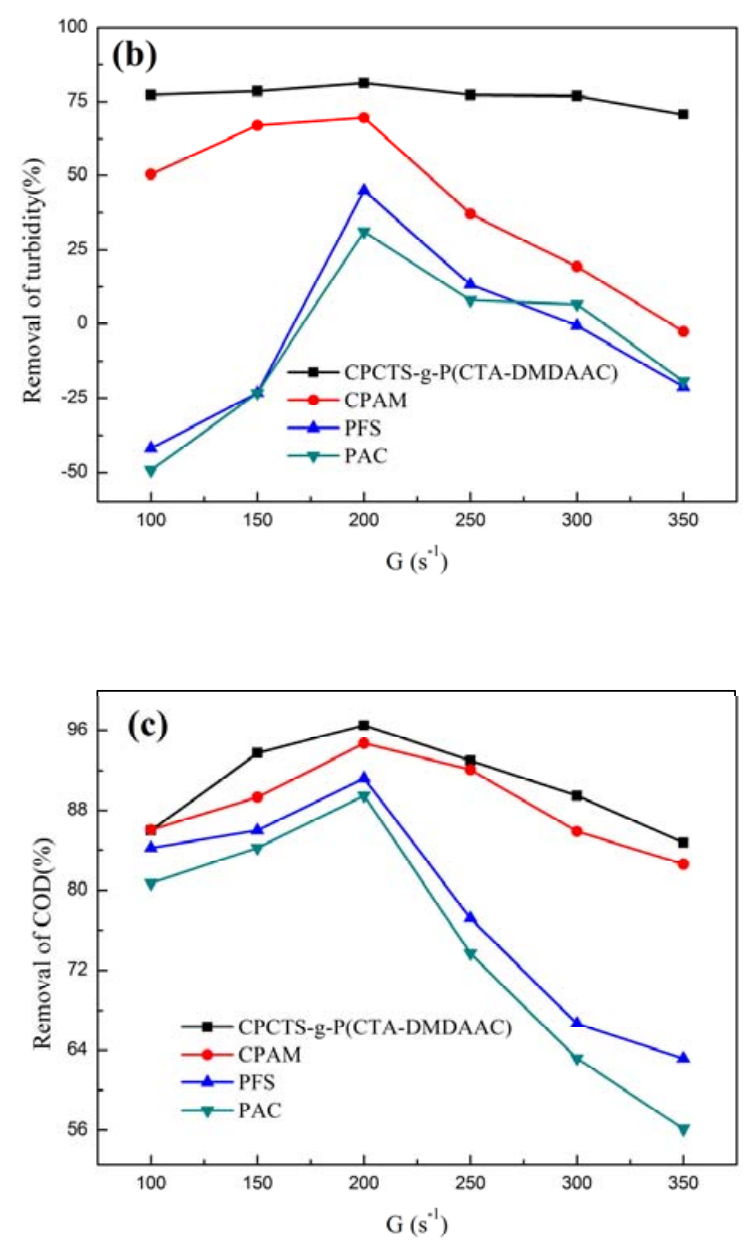

Figure 8. Effect of G value on flocculation properties: (a) Chl-a; (b) turbidity; (c) COD.

\subsubsection{Relationship between Optimal CPCTS-g-P (CTA-DMDAAC) dosage and Chl-a}

Relationship between optimal CPCTS-g-P (CTA-DMDAAC) dosage and Chl-a content is shown in Figure 9. The optimal CPCTS-g-P (CTA-DMDAAC) dosages for different Chl-a contents were investigated, and corresponding experimental data were obtained. The $\mathrm{R}^{2}$ of the linear fit equation was 0.502 , thereby indicating that CPCTS-g-P (CTA-DMDAAC) dosage had a certain relative relationship with Chl-a content [43]. Under some conditions, it can be used to predict the optimal CPCTS-g-P (CTA-DMDAAC) dosage for obtaining the maximum Chl-a removal rate [44,45].

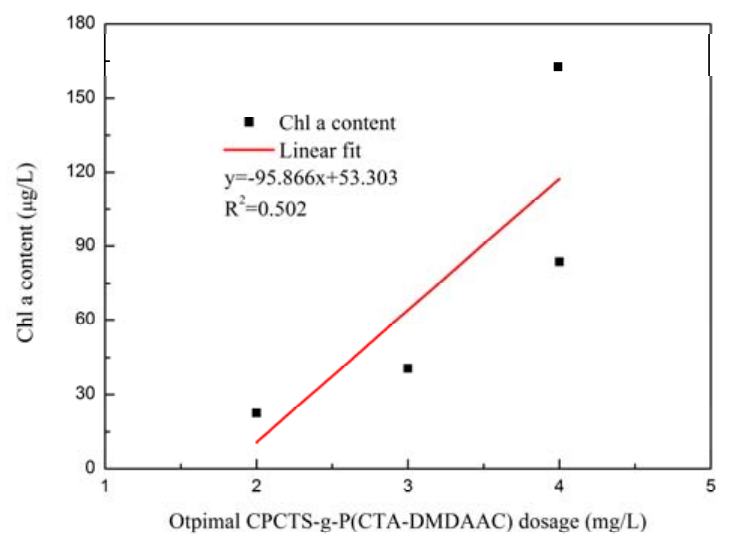

Figure 9. Relationship between optimal CPCTS-g-P (CTA-DMDAAC) dosage and Chl-a content. 


\section{Conclusions}

In this study, the ampholytic flocculant CPCTS-g-P (CTA-DMDAAC) was synthesized, and its flocculation performance was verified by the investigation of algal removal. The optimum conditions for the synthesis of CPCTS-g-P (CTA-DMDAAC) were as follows: monomer concentration of $25 \%$; 1:4 ratio of CPCTS and cationic degree; cationic degree of $40 \%$; photoinitiation time of $2 \mathrm{~h}$; photoinitiator concentration of $0.5 \%$; and, $\mathrm{pH}$ value of 4 . After the optimization of the flocculation process to achieve the maximum removal rates of $\mathrm{Chl}-\mathrm{a}$ and COD, the maximum removal rates of $\mathrm{Chl}-\mathrm{a}$ and COD that were obtained by CPCTS-g-P (CTA-DMDAAC) were $98.8 \%$ and $96.5 \%$ at $4 \mathrm{mg} / \mathrm{L}, \mathrm{pH} 7$ and $\mathrm{G}$ value of $200 \mathrm{~s}^{-1}$, respectively. Finally, by comparing with the commercially available flocculants CPAM, PFS and PAC, the experimental results demonstrated that CPCTS-g-P (CTA-DMDAAC) had a higher removal capacity of Chl-a and COD. All of the results and discussion demonstrated that the ampholytic flocculant CPCTS-g-P (CTA-DMDAAC) had excellent performance for algae removal. In addition, the natural modified flocculant showed high efficiency of flocculation, which should be given more interest in further research.

Author Contributions: C.L. and Y.S. conceived and designed the experiments; L.C., M.R. and Y.S. performed the experiments; Y.X., W.S. and Y.S. analyzed the data; W.S., H.Z. and Y.S. contributed reagents/materials/analysis tools; L.C. and Y.S. wrote the paper.

Acknowledgments: This research was supported by the National Natural Science Foundation of China (No. 51508268), the National Key Research and Development Program of China (2017YFB0602500), the Natural Science Foundation of the Jiangsu Province in China (No. BK20150951; No. BK20150959; BK20160689), and China Postdoctoral Science Foundation (No. 2016M591835).

Conflicts of Interest: The authors declare no conflict of interest.

\section{References}

1. Srinivas, R.; Singh, A.P. An integrated fuzzy-based advanced eutrophication simulation model to develop the best management scenarios for a river basin. Environ. Sci. Pollut. Res. 2018, 25, 9012-9039. [CrossRef] [PubMed]

2. $\quad$ Padedda, B.M.; Sechi, N.; Lai, G.G.; Mariani, M.A.; Pulina, S.; Sarria, M.; Satta, C.T.; Virdis, T.; Buscarinu, P.; Luglie, A. Consequences of eutrophication in the management of water resources in Mediterranean reservoirs: A case study of Lake Cedrino (Sardinia, Italy). Glob. Ecol. Conserv. 2017, 12, 21-35. [CrossRef]

3. Ding, S.; Chen, M.; Gong, M.; Fan, X.; Qin, B.; Xu, H.; Gao, S.S.; Jin, Z.; Tsang, D.C.W.; Zhang, C. Internal phosphorus loading from sediments causes seasonal nitrogen limitation for harmful algal blooms. Sci. Total Environ. 2018, 625, 872-884. [CrossRef] [PubMed]

4. Li, C.; Yu, H.; Tabassum, S.; Li, L.; Mu, Y.; Wu, D.; Zhang, Z.; Kong, H.; Xu, P. Effect of calcium silicate hydrates coupled with Myriophyllum spicatum on phosphorus release and immobilization in shallow lake sediment. Chem. Eng. J. 2018, 331, 462-470. [CrossRef]

5. Chen, M.; Ding, S.; Chen, X.; Sun, Q.; Fan, X.; Lin, J.; Ren, M.; Yang, L.; Zhang, C. Mechanisms driving phosphorus release during algal blooms based on hourly changes in iron and phosphorus concentrations in sediments. Water Res. 2018, 133, 153-164. [CrossRef] [PubMed]

6. Zhang, Y.; Zhou, Y.; Shi, K.; Qin, B.; Yao, X.; Zhang, Y. Optical properties and composition changes in chromophoric dissolved organic matter along trophic gradients: Implications for monitoring and assessing lake eutrophication. Water Res. 2018, 131, 255-263. [CrossRef] [PubMed]

7. Huang, J.; Arhonditsis, G.B.; Gao, J.; Kim, D.K.; Dong, F. Towards the development of a modeling framework to track nitrogen export from lowland artificial watersheds (polders). Water Res. 2018, 133, 319-337. [CrossRef] [PubMed]

8. Muri, G.; Cermelj, B.; Jaćimović, R.; Ravnikar, T.; Smuc, A.; Turšic, J.; Vreča, P. Factors that contributed to recent eutrophication of two Slovenian mountain lakes. J. Paleolimnol. 2018, 59, 411-426. [CrossRef]

9. Rodrigo, M.A.; Valentín, A.; Claros, J.; Moreno, L.; Segura, M.; Lassalle, M.; Vera, P. Assessing the effect of emergent vegetation in a surface-flow constructed wetland on eutrophication reversion and biodiversity enhancement. Ecol. Eng. 2018, 113, 74-87. [CrossRef] 
10. Liu, B.; Chen, X.; Zheng, H.; Wang, Y.; Sun, Y.; Zhao, C.; Zhang, S. Rapid and efficient removal of heavy metal and cationic dye by carboxylaterich magnetic chitosan flocculants: Role of ionic groups. Carbohyd. Polym. 2018, 181, 327-336. [CrossRef] [PubMed]

11. Gonzalez-Torres, A.; Rich, A.M.; Marjo, C.E.; Henderson, R.K. Evaluation of biochemical algal floc properties using Reactance Fourier-Transform Infrared Imaging. Algal Res. 2017, 27, 345-355. [CrossRef]

12. Ummalyma, S.B.; Gnansounou, E.; Sukumaran, R.K.; Sindhu, R.; Pandey, A.; Sahoo, D. Bioflocculation: An alternative strategy for harvesting of microalgae-An overview. Bioresour. Technol. 2017, 242, 227-235. [CrossRef] [PubMed]

13. Li, Y.; Xu, Y.; Zheng, T.; Wang, H. Amino acids in cell wall of Gram-positive bacterium Micrococcus sp. hsn08 with flocculation activity on Chlorella vulgaris biomass. Bioresour. Technol. 2018, 249, 417-424. [CrossRef] [PubMed]

14. Baresova, M.; Pivokonsky, M.; Novotna, K.; Naceradska, J.; Branyik, T. An application of cellular organic matter to coagulation of cyanobacterial cells (Merismopedia tenuissima). Water Res. 2017, 122, 70-77. [CrossRef] [PubMed]

15. Roselet, F.; Vandamme, D.; Roselet, M.; Muylaert, K.; Abreu, P.C. Effects of pH, Salinity, Biomass Concentration, and Algal Organic Matter on Flocculant Efficiency of Synthetic Versus Natural Polymers for Harvesting Microalgae Biomass. Bioenergy Res. 2017, 10, 427-437. [CrossRef]

16. Li, X.; Zheng, H.; Gao, B.; Zhao, C.; Sun, Y. UV-initiated polymerization of acid- and alkali-resistant cationic flocculant P(AM-MAPTAC): Synthesis, characterization, and application in sludge dewatering. Sep. Purif. Technol. 2017, 187, 244-254. [CrossRef]

17. Yeap, K.L.; Teng, T.T.; Poh, B.T.; Morad, N.; Lee, K.E. Preparation and characterization of coagulation/flocculation behavior of a novel inorganic-organic hybrid polymer for reactive and disperse dyes removal. Chem. Eng. J. 2014, 243, 305-314. [CrossRef]

18. Jia, S.; Yang, Z.; Yang, W.; Zhang, T.; Zhang, S.; Yang, X.; Dong, Y.; Wu, J.; Wang, Y. Removal of Cu(II) and tetracycline using an aromatic rings-functionalized chitosan-based flocculant: Enhanced interaction between the flocculant and the antibiotic. Chem. Eng. J. 2016, 283, 495-503. [CrossRef]

19. Martínez-Quiroz, M.; López-Maldonado, E.A.; Ochoa-Terán, A.; Oropeza-Guzman, M.T.; Pina-Luis, G.E.; Zeferino-Ramírez, J. Innovative uses of carbamoyl benzoic acids in coagulation-flocculation's processes of wastewater. Chem. Eng. J. 2017, 307, 981-988. [CrossRef]

20. Li, X.; Zheng, H.; Wang, Y.; Sun, Y.; Xu, B.; Zhao, C. Fabricating an enhanced sterilization chitosan-based flocculants: Synthesis, characterization, evaluation of sterilization and flocculation. Chem. Eng. J. 2017, 319, 119-130. [CrossRef]

21. Ortona, O.; D'Errico, G.; Mangiapia, G.; Ciccarelli, D. The aggregative behavior of hydrophobically modified chitosans with high substitution degree in aqueous solution. Carbohydr. Polym. 2008, 74, 16-22. [CrossRef]

22. Ruocco, N.; Frielinghaus, H.; Vitiello, G.; D’Errico, G.; Leal, L.G.; Richter, D.; Ortona, O.; Paduano, L. How hydrophobically modified chitosans are stabilized by biocompatible lipid aggregates. J. Colloid Interface Sci. 2015, 452, 160-168. [CrossRef] [PubMed]

23. Sun, Y.; Zhu, C.; Sun, W.; Xu, Y.; Xiao, X.; Zheng, H.; Wu, H.; Liu, C. Plasma-initiated polymerization of chitosan-based CS-g-P(AM-DMDAAC) flocculant for the enhanced flocculation of low-algal-turbidity water. Carbohydr. Polym. 2017, 164, 222-232. [CrossRef] [PubMed]

24. Martínez-Quiroz, M.; López-Maldonado, E.A.; Ochoa-Terán, A.; Pina-Luis, G.E.; Oropeza-Guzman, M.T. Modification of chitosan with carbamoyl benzoic acids for testing its coagulant-flocculant and binding capacities in removal of metallic ions typically contained in plating wastewater. Chem. Eng. J. 2018, 332, 749-756. [CrossRef]

25. Du, H.; Yang, Z.; Tian, Z.; Huang, M.; Yang, W.; Zhang, L.; Li, A. Enhanced removal of trace antibiotics from turbid water in the coexistence of natural organic matters using phenylalanine-modified-chitosan flocculants: Effect of flocculants' molecular architectures. Chem. Eng. J. 2018, 333, 310-319. [CrossRef]

26. Zhuang, S.; Yin, Y.; Wang, J. Removal of cobalt ions from aqueous solution using chitosan grafted with maleic acid by gamma radiation. Nucl. Eng. Technol. 2018, 50, 211-215. [CrossRef]

27. Feng, B.; Peng, J.; Zhu, X.; Huang, W. The settling behavior of quartz using chitosan as flocculant. J. Mater. Res. Technol. 2017, 6, 71-76. [CrossRef]

28. Wang, H.; Zhang, L. Efficient cleaning of cyanobacterial blooms using flocculants made of modified waterwork sludges. Environ. Chem. Lett. 2018, 16, 265-273. [CrossRef] 
29. Wu, H.; Yang, R.; Li, R.; Long, C.; Yang, H.; Li, A. Modeling and optimization of the flocculation processes for removal of cationic and anionic dyes from water by an amphoteric grafting chitosan-based flocculant using response surface methodology. Environ. Sci. Pollut. Res. 2015, 22, 13038-13048. [CrossRef] [PubMed]

30. Ma, X.; Zheng, H.; Zhou, W.; Liu, Y.; Chen, P.; Ruan, R. Enhanced Harvesting of Chlorella vulgaris Using Combined Flocculants. Appl. Biochem. Biotechnol. 2016, 180, 791-804. [CrossRef] [PubMed]

31. Peng, S.; Jiang, G.; Li, X.; Yang, L.; Liu, F.; He, Y. Flocculation of submicron particles in water-based drilling fluids by CMC-g-DMDAAC. J. Pet. Sci. Eng. 2018, 162, 55-62. [CrossRef]

32. Ibarra-Rodríguez, D.; Lizardi-Mendoza, J.; López-Maldonado, E.A.; Oropeza-Guzmán, M.T. Capacity of 'nopal' pectin as a dual coagulant-flocculant agent for heavy metals removal. Chem. Eng. J. 2017, 323, $19-28$. [CrossRef]

33. Lü, T.; Chen, Y.; Qi, D.; Cao, Z.; Zhang, D.; Zhao, H. Treatment of emulsified oil wastewaters by using chitosan grafted magnetic nanoparticles. J. Alloys Compd. 2017, 696, 1205-1212. [CrossRef]

34. Lu, X.; Xu, Y.; Sun, W.; Sun, Y.; Zheng, H. UV-initiated synthesis of a novel chitosan-based flocculant with high flocculation efficiency for algal removal. Sci. Total Environ. 2017, 609, 410-418. [CrossRef] [PubMed]

35. Lou, T.; Cui, G.; Xun, J.; Wang, X.; Feng, N.; Zhang, J. Synthesis of a terpolymer based on chitosan and lignin as an effective flocculant for dye removal. Colloids Surf. A 2018, 537, 149-154. [CrossRef]

36. Sun, Y.; Zhu, C.; Zheng, H.; Sun, W.; Xu, Y.; Xiao, X.; You, Z. Characterization and coagulation behavior of polymeric aluminum ferric silicate (PAFSi) for high concentration oily wastewater treatment. Chem. Eng. Res. Des. 2017, 119, 23-32. [CrossRef]

37. Dong, C.; Chen, W.; Liu, C. Flocculation of algal cells by amphoteric chitosan-based flocculant. Bioresour. Technol. 2014, 170, 239-247. [CrossRef] [PubMed]

38. Sun, Y.; Ren, M.; Zhu, C.; Xu, Y.; Zheng, H.; Xiao, X.; Wu, H.; Xia, T.; You, Z. UV-initiated graft copolymerization of cationic chitosan-based flocculants for treatment of zinc phosphate-contaminated wastewater. Ind. Eng. Chem. Res. 2016, 55, 10025-10035. [CrossRef]

39. Lama, S.; Muylaert, K.; Karki, T.B.; Foubert, I.; Henderson, R.K.; Vandamme, D. Flocculation properties of several microalgae and a cyanobacterium species during ferric chloride, chitosan and alkaline flocculation. Bioresour. Technol. 2016, 220, 464-470. [CrossRef] [PubMed]

40. Sun, Y.; Zheng, H.; Xiong, Z.; Wang, Y.; Tang, X.; Chen, W.; Ding, Y. Algae removal by flocculation process from algae-containing raw water and the fractal characteristic of flocs. Desalin. Water Treat. 2015, 56, 894-904. [CrossRef]

41. Gerchman, Y.; Vasker, B.; Tavasi, M.; Mishael, Y.; Kinel-Tahan, Y.; Yehoshua, Y. Effective harvesting of microalgae: Comparison of different polymeric flocculants. Bioresour. Technol. 2017, 228, 141-146. [CrossRef] [PubMed]

42. Zheng, H.; Sun, Y.; Zhu, C.; Guo, J.; Zhao, C.; Liao, Y.; Guan, Q. UV-initiated polymerization of hydrophobically associating cationic flocculants: Synthesis, characterization, and dewatering properties. Chem. Eng. J. 2013, 234, 318-326. [CrossRef]

43. Xiao, X.; Sun, Y.; Sun, W.; Shen, H.; Zheng, H.; Xu, Y.; Zhao, J.; Wu, H.; Liu, C. Advanced treatment of actual textile dye wastewater by Fenton-flocculation proces. Can. J. Chem. Eng. 2017, 95, 1245-1252. [CrossRef]

44. Ren, K.; Du, H.; Yang, Z.; Tian, Z.; Zhang, X.; Yang, W.; Chen, J. Separation and sequential recovery of tetracycline and $\mathrm{Cu}(\mathrm{II})$ from water using reusable thermoresponsive chitosan-based flocculant. ACS Appl. Mater. Interfaces 2017, 9, 10266-10275. [CrossRef] [PubMed]

45. Fujita, S.; Sakairi, N. Water soluble EDTA-linked chitosan as a zwitterionic flocculant for $\mathrm{pH}$ sensitive removal of $\mathrm{Cu}(\mathrm{II})$ ion. $R S C$ Adv. 2016, 6, 10385-10392. [CrossRef]

(C) 2018 by the authors. Licensee MDPI, Basel, Switzerland. This article is an open access article distributed under the terms and conditions of the Creative Commons Attribution (CC BY) license (http:/ / creativecommons.org/licenses/by/4.0/). 